\title{
Observing the solid Earth, oceans and land waters from space
}

\author{
A. Cazenave \\ LEGOS-CNES-CNRS-UPS, 18 avenue Edouard Belin, 31401 Toulouse Cedex 9, France
}

\begin{abstract}
In this article, we present a number of significant results related to the solid Earth and its fluid envelopes obtained in the recent years/decades using remote sensing techniques. We first discuss measurements of the Earth gravity field at different spatial scales and the recovery of seafloor topography from satellite altimetry. We briefly mention precise positioning results based on GPS and other space techniques, and applications to tectonic motions and crustal deformations. Next we discuss recent advances in ocean dynamics based on high-precision satellite altimetry missions, and focus on sea level rise. We also discuss how remote sensing techniques, including space gravimetry, inform on the mass balance of the ice sheets and corresponding contribution to sea level rise. As a final example, we report on the monitoring of surface water levels (lakes, rivers, floodplains) by satellite altimetry and on total land water storage change at river basin scale, using space gravimetry observations.
\end{abstract}

\section{Introduction}

Since many decades, remote sensing observations provide images of the Earth's atmosphere, now routinely used for weather forecast. In several other areas of Earth sciences, observations from space are also increasingly collected. For example, satellite monitoring of natural hazards, water resources, land use inventory, cartography, etc., are well-known applications of Earth observations from space. In solid Earth sciences also, satellite measurements have become of very high value. Only satellites have the capability of providing global observations over long time periods, and with high-frequency revisit time.

The Earth's is a complex system whose components (from the deep interior to the most external envelopes) interact on a broad range of spatial and temporal scales. For example, the core magnetic field generates the Earth's magnetosphere which protects the planet from nocive particles from the sun and galatic medium. Convective motions occurring inside the Earth's mantle are the main drivers of tectonic deformations of the Earth's crust as well as seismic and volcanic activity. Complex sea floor and land topography is a direct consequence of tectonic activity. Besides, mantle convection is also the main process causing the large-scale non-uniform gravity field. Oceans, atmosphere, cryosphere, hydrosphere (land waters) and biosphere, where are taking place life and climate phenomena, are also linked by complex interactions. The ocean circulation transports heat from one region to another and thus plays an important role in regulating the Earth's climate. Sea level rise caused by ocean warming and land ice melt is another example of interaction between oceans, land and ice sheets.

To understand all these processes and their interactions, sustained global-scale observations are needed. While in many instances, in situ observing systems are of very high value, to observe the Earth' system as a whole, only satellites can provide the required global monitoring.

Observations of the Earth system from space result primarily from remote sensing, e.g., imagery in different wavebands (visible, microwaves), with the goal of determining properties of 


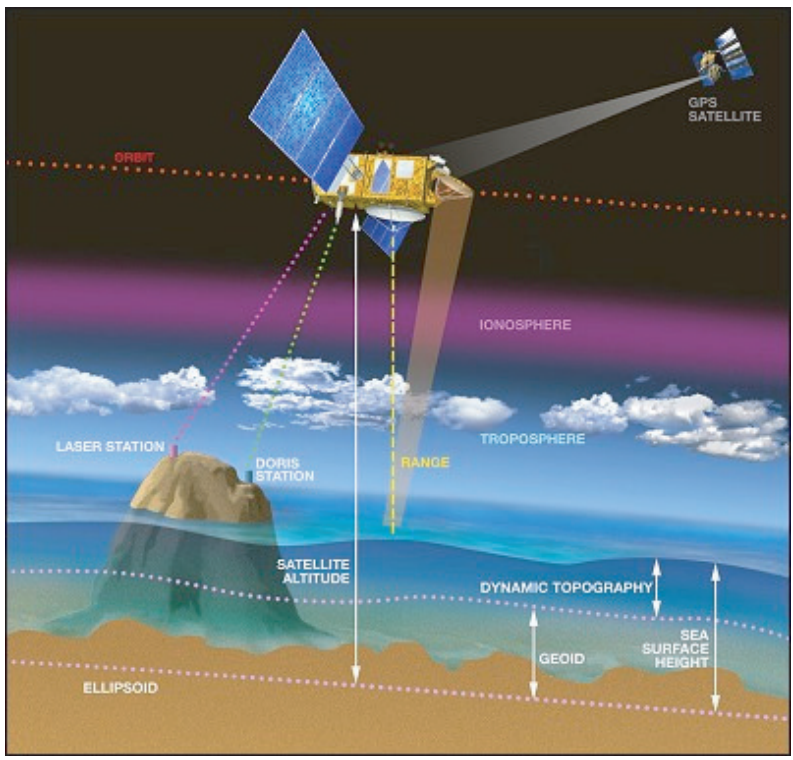

Fig. 1. Sketch of the satellite altimetry measurement principle.

studied objects from the radiations they reflect or emit. However, other approaches have been developed to study the physical properties of the planet: e.g., precise orbitography informing on the forces acting on artificial satellites, including the Earth's gravity field; tracking techniques like GPS (Global Positioning System), DORIS (Doppler Orbit Determination and Radiopositioning Intergrated on Satellite) and Synthetic Aperture Radar Interferometry (INSAR) for precise positioning and measurements of crustal deformations; onboard dedicated instruments for measuring specified Earth's parameters (e.g., radar altimetry for spatio-temporal change of ocean and land water surfaces, magnetometers for the magnetic field, etc.).

During the past two decades, numerous studies have used space techniques for studying solid Earth, ocean dynamics and sea level, land hydrology and cryosphere. In this paper we present examples of most recent advances obtained in some of these areas.

Section 2 is a brief overview of space techniques used in geodesy, oceanography and hydrology. Section 3 reviews progress realized in measuring the Earth gravity field from space during the past few decades and discuss applications of space geodesy techniques to tectonics studies. In section 4, major results about ocean dynamics and sea level rise are presented. Section 5 discusses the mass balance of the ice sheets measured by remote sensing techniques. Finally section 6 presents space techniques applications in large-scale land hydrology.

\section{Space techniques for geodesy, oceanography and land hydrology}

The main tools of space geodesy are distance and relative velocity measurements between ground geodetic stations and satellites (e.g., Satellite Laser Ranging, GPS, DORIS) as well as travel time of radio signals between satellites in different orbit. These so called tracking data are used to precisely determine the evolution of the satellite orbits with time. Knowledge of orbit departure from a pure Keplerian ellipse is then used to determine forces acting on the satellite, e.g. the Earth gravity field and its evolution with time. In addition to the orbit are also be determined position and velocity of the geodetic ground stations as well as parameters related to the reference frame (Earth rotation parameters and motion of the center of mass of the Earth). Space geodesy also uses onboard devices such as radar and optical imagers which provide direct mapping of Earth's surface properties. Another space technique of great interest for Earth studies is radar altimetry. The concept of the satellite altimetry measurement is rather straightforward (Fig. 1). The onboard radar altimeter transmits a short pulse of microwave 
radiation with known power towards the nadir. Part of the incident radiation reflects back to the altimeter. Measurement of the round-trip travel time provides the height of the satellite above the instantaneous sea surface (called altimeter range $\mathrm{R}$ ). The quantity of interest in oceanography is the height $h$ of the instaneous sea surface above a fixed reference surface (typically a conventional reference ellipsoid). This quantity is simply the difference between the altitude $\mathrm{H}$ of the satellite above the reference ellipsoid and the altimeter range $\mathrm{R}: \mathrm{h}=\mathrm{H}-\mathrm{R}$. $\mathrm{H}$ is computed through precise orbit determination, a long-tested approach in space geodesy which combines accurate modelling of the dynamics of the satellite motion and tracking measurements (Satellite Laser Ranging, GPS, DORIS) between the satellite and observing stations on Earth or other observing satellites. The range $\mathrm{R}$ from the satellite to sea surface must be corrected for travel delays through ionosphere and troposphere as well as biases between the mean electromagnetic scattering surface and sea surface at air-sea interface. Other corrections due to a number of geophysical effects must also be subtracted. The first altimeter satellite Geos 3 was launched in 1975. Since then, several altimetry missions have flown with the purpose of studying the oceans from space (e.g., Seasat, 1978; Geosat, 1985-1989). However, until the early 1990s, satellite altimetry has been more useful to geophysics than oceanography. In effet, during the early missions, the orbital error (on $\mathrm{H}$ ) was so large (from several decimeters to $1 \mathrm{~m}$ ) that uncertainty on height $\mathrm{h}$ of the instaneous sea surface totally prevented from detecting phenomena associated with ocean dynamics. In the early 1990s started the era of precise altimetry dedicated to space oceanography [1]: ERS-1/2 launched in 1991 and 1995 respectively, and especially the Topex-Poseidon (1992-2006), Jason-1 and Jason-2 missions launched in 2001 and 2008 respectively. Over the years, technological improvements have decreased considerably the instrumental noise. Moreover, thanks to a concerted effort in precise modelling of the geophysisical and environmental corrections, sea surface height measurement error has decreased to the 3-4 cm level for Topex/Poseidon [1]. For Jason-1 and Jason-2, it is even smaller, in the range $1-2 \mathrm{~cm}$.

Recently a new space technique (gravimetry from space) has provided for the first time measurements of temporal variations of the Earth gravity field. The first space gravimetry mission, GRACE, was launched in 2002 [2]. It consists of a pair of satellites whose mutual distance, absolute positions and velocities are continuously monitored. These tracking data are analyzed by the GRACE project to provide monthly solutions of the Earth gravity field. The static component of the gravity field due to solid Earth contributions (see section 3) explains nearly 99 per cent of the monthly gravity signal. Superimposed time-variable component is generally expressed as anomaly with respect to the static field, the latter being approximated by the temporal mean of a multi-year series of GRACE monthly solutions. As gravity is an integral of mass, these spatio-temporal gravity variations represent horizontal mass redistributions, to the extent they are assumed to be caused by surface mass changes. On time scales ranging from months to decades, surface mass redistribution predominantly results from water mass exchange among the surface fluid envelopes of the Earth (oceans, atmosphere, ice caps, continental reservoirs) and is related to climate variability and anthropogenic forcing.

\section{Applications to solid Earth}

\subsection{Earth gravity field, marine geoid and seafloor topography}

Before the artificial satellite era, the Earth gravity field was very poorly known globally. The gravity field can be visualized through a surface called geoid, an equipotential surface the Earth gravity field which coincides with the mean sea level at rest. Undulations of the geoid represent the heterogeneous distribution of the matter inside the Earth. To a first approximation the geoid coincides with the 'mean' shape of the Earth if it were totally covered by water. While the sphericity of the Earth had been established very early in Antic times, the Greek geometer Erathostenes in the $3^{\text {rd }}$ century before Christ performed the first measurement of the Earth size from observations of the sun's position at different sites. His estimate of the Earth radius was remarkably close to what we know today. It is only 2000 years later, in the $18^{\text {th }}$ century, that scientific expeditions to Laponie and Perou established that the Earth is a flattened body, 


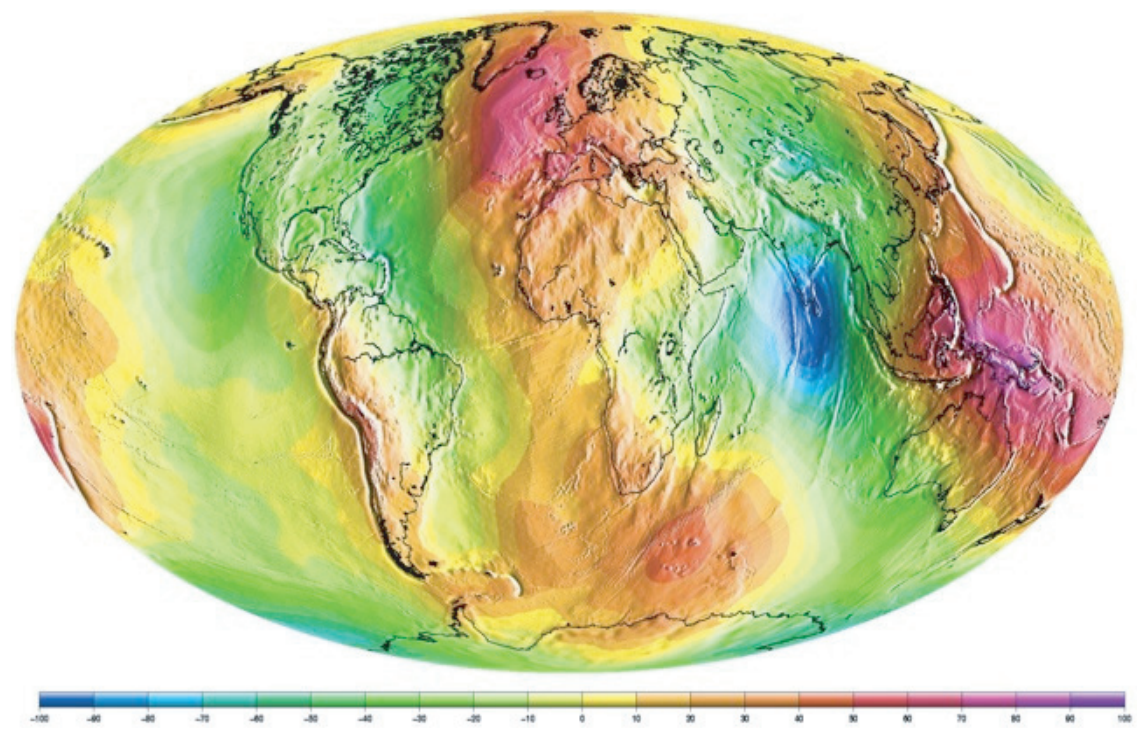

Fig. 2. Long-wavelength geoid (scale in $\mathrm{m}$ ) referred to the WGS84 reference frame. It is based on the latest version of the Earth Gravity Model (EGM2008, [3]).

an observation which superbly confirmed the hypothesis proposed by Newton a few decades earlier from theoretical arguments. Then until the middle of the $20^{\text {th }}$ century almost nothing else was known about the shape of the Earth. In the late 50s however, observations provided by the first artificial satellites have radically changed our view of the shape of the Earth. Satellites first revealed that the Earth shape is quite irregular and much more complex than previously thought. This shape in fact reflects the spatial variations of the Earth gravity field, which is itself a result of the heterogeneous distribution of the matter inside and at the surface of the planet. Early determination of the Earth gravity field were based on precise determination of satellite orbits (and their evolution with time) using distance and relative velocity measurements between ground geodetic stations and satellites as well as travel time of radio signal between satellites in different orbits (see section 2). Knowledge of orbits was then used to determine forces acting on the satellite, the dominant one being the Earth gravity field. Fig. 2 is a map of the long-wavelength geoid based on satellite and in situ data. It shows the broad geoid highs over the western Pacific, North Atlantic and South Africa, as well as the geoid low south of India. Amplitudes of these geoid undulations reach 50 to $100 \mathrm{~m}$.

Interpretation of these long-wavelength geoid undulations has led to major results about the large scale convective structure of the mantle and the determination of mantle viscosity variation with depth (e.g., [4]). Viscosity is indeed a crucial parameter in mantle convection modeling. During the past two decades, geophysicists have developed models of the convective circulation inside the mantle. These models use density anomalies inferred from seismic tomography as input. The mantle viscosity is determined either from forward modeling via the comparison between theoretical and observed long wavelength geoid or via an inverse problem. To fit the geoid data, a low viscosity layer beneath the lithosphere needs to be invoked as well as a viscosity increase by a factor of $\sim 30$ at the upper mantle-lower mantle interface. Such a viscosity stratification has profound implication on the structure of mantle convection and more generally on the dynamics of the mantle. For example, the longest wavelengths of the geoid can now be satisfactorily explained by ancient lithospheric slabs subducting throughout the whole mantle. Corresponding density distribution agrees with that inferred from seismic tomography and is compatible with large-scale mantle convection with bottom heating [4].

At short and medium spatial wavelengths, geoid undulations have been derived by direct mapping of the mean sea surface by satellite altimetry from the Seasat, Geosat and ERS-1 missions. In effect, the precision of early altimetry missions was sufficient to map the marine geoid which typical undulations range from $\sim 1 \mathrm{~m}$ to several tens $\mathrm{m}$. Fig. 3 shows a map of the 


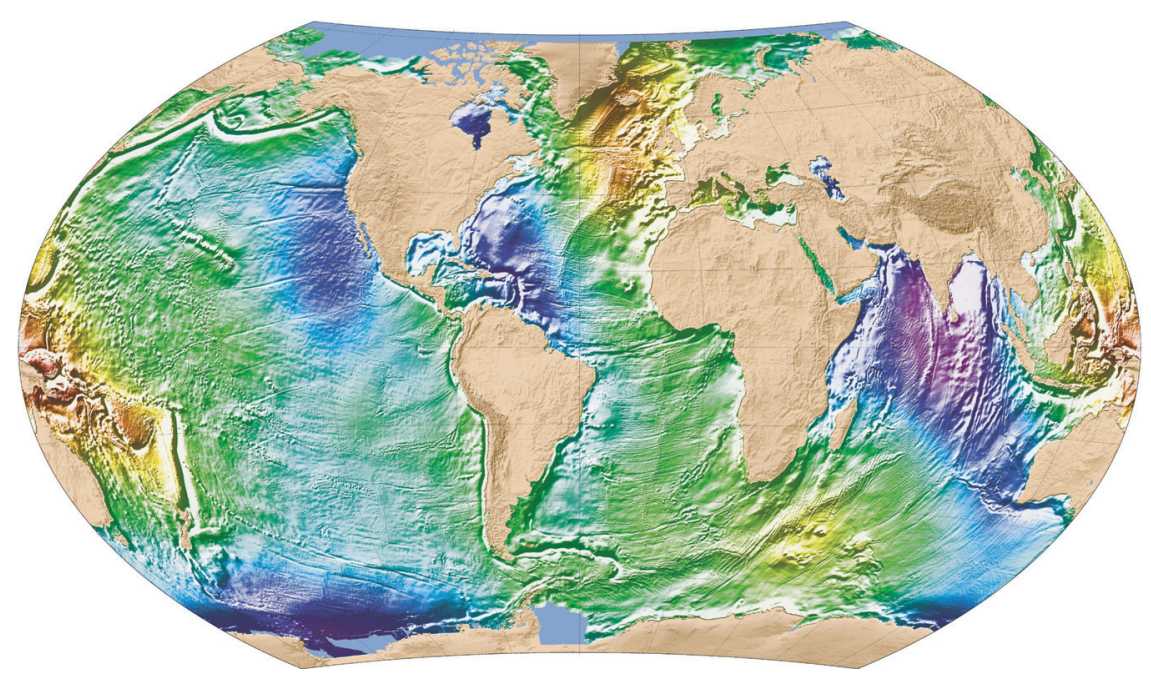

Fig. 3. The marine geoid mapped by satellite altimetry [5].

high-resolution marine geoid which reflects the gravitational signature of seafloor topography. It also contains information on the mass distribution inside the underlying lithosphere and asthenosphere.

During the past 20 years, numerous marine geophysics studies have been carried out and important results concerning the mechanical and thermal structure of lithospheric plates have been obtained (see [6] for a review). It has been shown for example that the upper part of lithospheric plates which is elastic, increases in thickness with plate age. From this result, it has been possible to infer age of volcanoes and deduce the type of tectonic setting on which they formed (either in the vicinity of a spreading center or on an old plate). Numerous seamounts have been discovered. In the Pacific ocean alone, about 8000 seamounts have been identified, half of them only being known previously. This allowed quantifying the magmatic production through time. Unknown tectonic features have been discovered such as extinct spreading centers, fossil subduction zones, and elongated geoid undulations probably related to sublithospheric small scale convection. Satellite altimetry has also revealed the complex 3-D structure of mid-ocean ridges, offering new constraints on models of magma supply under spreading centers. These maps have also been widely used for plate tectonic reconstruction because they provide very precise information on present and past tectonic plate boundaries. Another product of dense satellite altimetry is the recovery of the seafloor topography, up to now very poorly known (e.g., $[7,8])$. Knowledge of seafloor topography globally has a lot of applications not only in marine geophysics but also in oceanography, oil and petroleum exploration, fishing, etc.

\subsection{Tectonic plate motions and crustal deformations}

During the two past decades, measurements of crustal deformations at various spatial scales from space has revolutionized tectonic studies. Optical imagery from the Landsat and Spot satellites has provided global mapping of active faults in continental areas, with a ground resolution of a few meters. A well-studied region is the India-Asia collision belt where remote detection of numerous active faults has taken place. Analyses have established that Tibet is moving at a mean rate of $2 \mathrm{~cm} / \mathrm{yr}$ southeastward, providing constraints on the mechanical behaviour of the continental lithosphere. Optical imagery is also important for identification of new faults which have escaped seismic detection because of recent inactivity. Over the past two decades, most of the tectonically active deformation areas of the world have been surveyed by dense GPS networks. The presently reached precision of GPS allows crustal deformations to be measured at the level of $1 \mathrm{~mm} / \mathrm{yr}$ or better. Numerous studies have used GPS in tectonic active areas to investigate current crustal motions as well co-seismic, post-seismic and interseismic 
deformations which determination provides strong constraints on rheological models of crust and lithosphere at plate boundaries and thus contribute to earthquake hazard assessment (e.g., [9]).

Another very powerful space technique for measuring crustal deformation is INSAR. By comparing SAR (Synthetic Aperture Radar) images of the same area at two different epochs (i.e., from different satellite flights over the area), it is possible to quantify surface deformation. The method is based on the interference pattern caused by the difference in phase between the two images. Corresponding interferogram is a contour map of the change in distance between the ground and the satellite, thus of surface deformation. Compared to GPS, the spatial resolution is incredibly higher, with a precision of about the same order of magnitude. During the past 15 years, the INSAR technique has been applied to measure co- and post-seismic deformations, movements of glaciers and ice sheets, landslides, ground subsidences due to oil or water pumping, and volcanic deformation (e.g., [10]).

Other important results concern the determination of present-day large scale tectonic plate motions. Analyses based on satellite laser ranging, VLBI (Very Long Baseline Interferometry), GPS and DORIS data have indicated that contemporary plate motions agree well with geological motions of the past 3 million years. This finding provides a spectacular confirmation of the tectonic plate theory which assumes that plate motions are stationary. This means that although motions at plate boundaries are episodic, the viscous mantle below the plates damps out the transient motions, leading to steady large scale motions. This is quite important for seismic hazard analysis because motions measured on various time scales can indeed be combined to study the seismic cycle.

\section{Oceanography from space}

Satellite altimetry has revolutionized ocean dynamics in providing high-precision, highresolution measurements of the ocean surface topography with global coverage and a revisit time of a few days. The launch of the Topex/Poseidon satellite in 1992 opened the era of highprecision altimetry, allowing for the first time mapping of the sea surface height with a $1-2 \mathrm{~cm}$ accuracy for a single measurement. Together with the data of its successors, Jason-1 and Jason2 , we now have at our disposal a $>15$-year long data set of very high value for studying ocean circulation (because of geostrophy, sea surface height measurements can be translated in terms of ocean circulation), ocean dynamics and sea level [1].

\subsection{Ocean dynamics}

Topex/Poseidon data have been used together with sea surface temperature data and surface wind velocities to analyze the mechanisms responsible for the particularly strong ENSO (El Nino-Southern Oscillation) event that occurred in 1997-1998 (ENSO is the largest climate perturbation of the coupled ocean-atmosphere system that occurs at 4-7 years time intervals in the tropical Pacific, with a zonal displacement of the western Pacific warm pool towards the eastern Pacific; while affecting predominantly the tropical Pacific, ENSO has worldwide climatic consequences through atmospheric teleconnections). For the first time in 1997-1998, an ENSO event was totally monitored from space, from its initialisation to is decay (e.g., [11]). Studies clarified the role of equatorial waves in the movement of the warm pool and the reflection of Kelvin waves into Rossby waves at the eastern boundaries of the Pacific ocean, leading to significant revision of existing ENSO theories. The new capabilities of observing key variables from space in the ENSO process has led to the advancement of ENSO prediction. Another important contribution of satellite altimetry concerns Rossby waves dynamics, in particular evidence of faster than expected wave speed propagation leading to revision in the theories. But perhaps the most important discovery from satellite altimetry is the very strong mesoscale variability observed almost everywhere in ocean basins, indicating that eddy energy generally exceeds the energy of the mean flow by an order of magnitude or more. These observations have provided new insights into eddy dynamics and its role in the ocean circulation, heat and salt transport, and the possible coupling with the atmosphere [11]. Sea surface height 


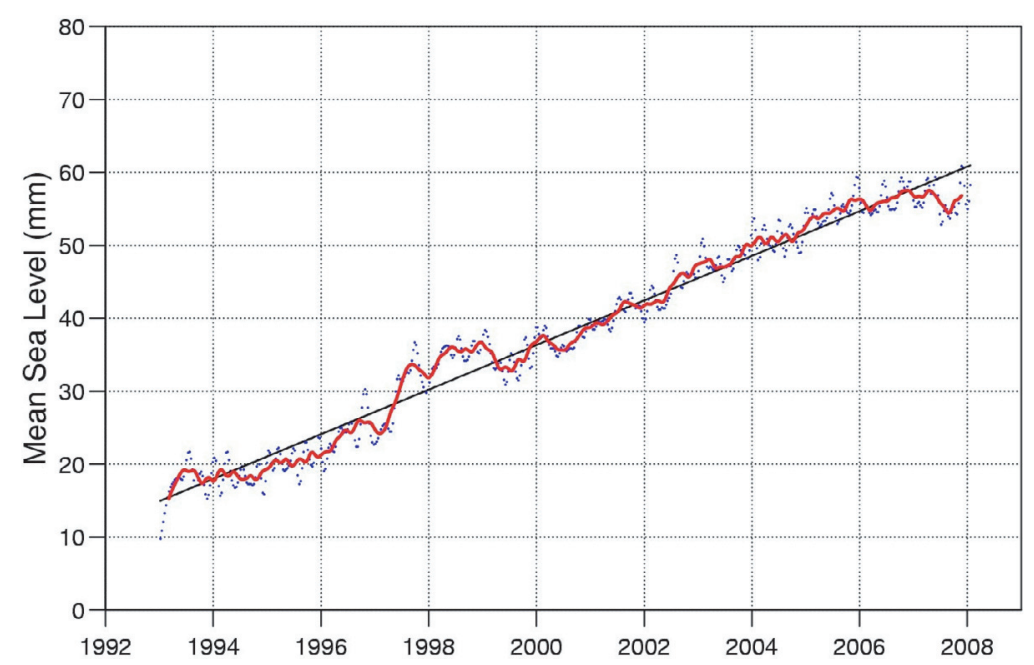

Fig. 4. Global mean sea level curve based on Topex/Poseidon and Jason-1 altimetry. Raw 10-day values (blue dots); smoothed curve (red); linear trend (black) (source: CLS-LEGOS).

measurements from Topex/Poseidon and Jason-1 missions are currently assimilated into global ocean circulation models to provide realistic information on the $3-\mathrm{D}$ ocean circulation and its evolution with time (e.g., $[12,13])$.

\subsection{Sea level change from satellite altimetry}

\subsubsection{Sea level observations}

While global mean sea level had remained almost stable during the 3 last millennia (subsequently to the last deglaciation initiated $\sim 18000$ years ago), tide gauge measurements available since the late $19^{\text {th }}$ century have indicated significant sea level rise during the $20^{\text {th }}$ century, at a rate of $\sim 1.7 \mathrm{~mm} / \mathrm{yr}$ (e.g., [14-16]). Since early 1993, sea level variations are now accurately measured by satellite altimetry (Topex/Poseidon, Jason-1 and Jason-2 missions). This $\sim 15$ year-long data set shows that, in terms of global mean, sea level continues to rise (Fig. 4). The linear trend computed over the 1993-2008 time span amounts $3.0+/-0.1 \mathrm{~mm} / \mathrm{yr}[17,18]$. A small correction of $-0.3 \mathrm{~mm} / \mathrm{yr}$ due to the global deformation of ocean basins in response to glacial isostatic adjustment (GIA) [20] has to be subtracted to the above trend, leading to an estimated rate of sea level rise of $3.3+/-0.4 \mathrm{~mm} / \mathrm{yr}$ for $1993-2008$. This eventually suggests that sea level rise is currently accelerating in response to global warming. However decadal sea level fluctuations are commonly observed in long-term tide gauge records, so that we cannot exclude that the high rate of sea level rise reported by satellite altimetry over the last 15 years simply reflects decadal variability. The $0.1 \mathrm{~mm} / \mathrm{yr}$ uncertainty represents the formal error. According to Mitchum et al. [19], comparison between altimetry-based sea level and tide gauge records over their overlapping time span suggests a more realistic error of $0.4 \mathrm{~mm} / \mathrm{yr}$.

Tide gauges data had previously indicated that sea level is not rising uniform. However, only the global coverage of altimeter satellites allows global mapping of the geographical variability in the rates of sea level change. Fig. 5 shows the spatial patterns in sea level trends computed over 1993-2007 with Topex/Poseidon and Jason-1 altimetry data. Over this time span, important regional variability is visible, a few regions-in particular the Western Pacific-exhibiting rates of sea level rise up to 5 times the global mean. In other regions (e.g., the Eastern Pacific) sea level has been dropping during that period. 


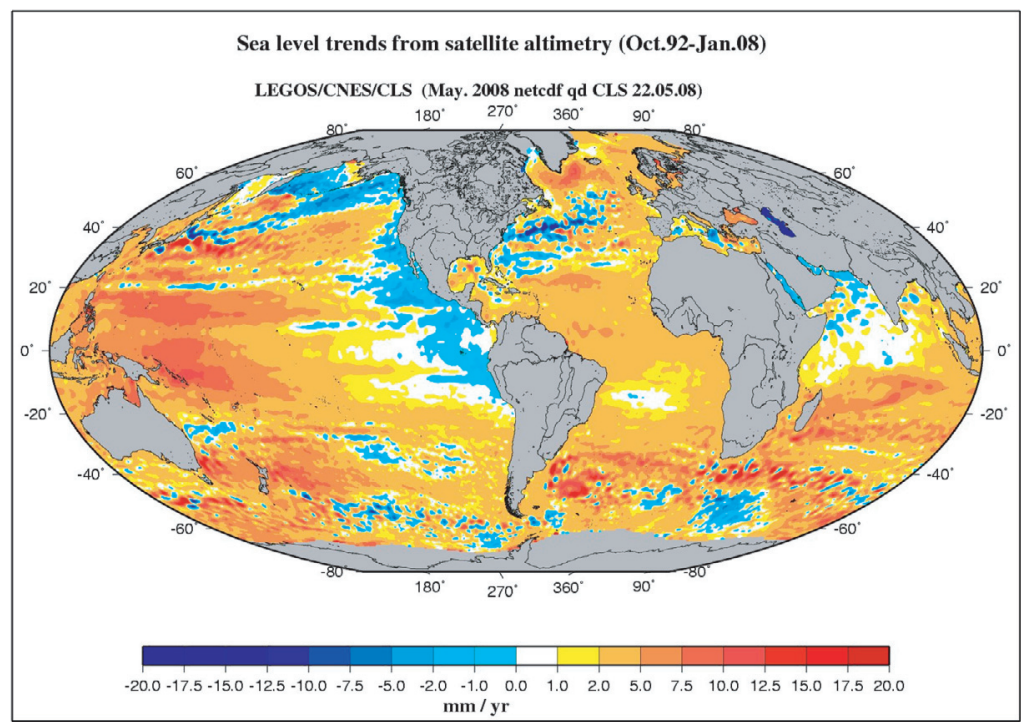

Fig. 5. Geographical distribution of rates of sea level change (i.e., sea level trends) over 1992-2008 from satellite altimetry. Higher rates than average (in red) are observed in the western Pacific, Austral ocean and North Atlantic. Negative sea level trends correspond to regions in blue (source: CLS-LEGOS).

\subsubsection{Causes of sea level rise}

At interannual to decadal time scales, two main factors contribute to sea level rise: thermal expansion of sea waters due to ocean warming, and water mass input from land ice melt and land water reservoirs.

Analyses of in situ ocean temperature data collected by ships, buoys and moorings over the past 50 years indicate that heat content of the ocean has increased significantly between 1950 and 2000 [21]. Ocean warming has led to thermal expansion of the oceans, hence sea level rise. Estimates based on available ocean temperature data down to $\sim 700 \mathrm{~m}$, indicate that ocean thermal expansion can explain about $25 \%$ of the observed sea level rise over the last 50 years [22]. This number is likely a lower bound, due to lack of hydrographic data in remote regions of the southern hemisphere and in the deep ocean (below $1000 \mathrm{~m}$ ). For the recent years (1993-2003), the thermal expansion contribution has increased and explains about half of the observed rate of sea level rise (e.g., [22-24]), leaving another half (i.e., $1.5 \mathrm{~mm} / \mathrm{yr}$ ) due to ocean mass change.

Being very sensitive to global warming, mountain glaciers and small ice caps have retreated worldwide in the recent decades, with significant acceleration during the 1990s. From mass balance studies of a large number of glaciers, several studies have estimated glaciers melting contribution to sea level, on the order of $0.5 \mathrm{~mm} / \mathrm{yr}$ since 1960 and $0.8 \mathrm{~mm} / \mathrm{yr}$ for 1993-2003 (e.g., $[25,26])$.

Remote sensing observations have shown that Greenland and Antarctica are currently loosing ice mass (see section 5). Accelerated ice mass loss is reported in coastal regions of southern Greenland and over West Antarctica. For the 1993-2003 time span, Greenland and Antarctica ice sheets have contributed by $0.2+/-0.1 \mathrm{~mm} / \mathrm{yr}$ and $0.2+/-0.2 \mathrm{~mm} / \mathrm{yr}$ to sea level rise [24]. This contribution is modest, but has clearly accelerated in the recent years (e.g., [26,27]).

Change in land water storage, due to natural climate variability and human activities (i.e., anthropogenic changes in the amount of water stored in soils, reservoirs and aquifers as a result from dam building, underground water mining, irrigation, urbanization, deforestation, etc.) is another potential contribution to sea level change. Model-based estimates of land water storage change caused by natural climate variability suggest no long-term contribution to sea level for the past few decades, although interannual/decadal fluctuations may have been significant (e.g., [28]). For the recent years, GRACE observations can be used to estimate the total 
(i.e., due to climate variability and human activities) land water contribution to sea level. Ramillien et al. [29] estimated water volume change in the largest river basins worldwide from GRACE and found a net negative water volume change (i.e., water loss) over 2003-2007, corresponding to $0.2+/-0.1 \mathrm{~mm} / \mathrm{yr}$ sea level rise.

For the decade 1993-2003, the sum of climate contributions (ocean thermal expansion, glaciers melting and ice sheet mass loss) closely explains the observed rate of sea level rise. Since about 2003, thermal expansion has had a break whereas sea level has continued to rise, although at a slightly reduced rate compared to the previous decade [30]. Recent increase in glacier melting and mass loss from the ice sheets appear able to account alone for the rise in sea level reported over the last five years. For example, Meier et al. [26] report accelerated glacier melting since 2003 , leading to $1.1+/-0.25 \mathrm{~mm} / \mathrm{yr}$ equivalent sea level rise in year 2006 . The mass balance of the ice sheets has been recently re-evaluated using GRACE and other remote sensing techniques. Rignot et al. [27] find an Antarctica contribution to sea level of $0.56 \mathrm{~mm} / \mathrm{yr}$ for year 2006, in good agreement with GRACE-based estimate $(0.55+/-0.06 \mathrm{~mm} / \mathrm{yr},[30])$. GRACE data also suggest an increased contribution from Greenland (of $0.4+/-0.05 \mathrm{~mm} / \mathrm{yr}$, $[28]$ ). Summing all land ice and land waters components leads to $2.2+/-0.25 \mathrm{~mm} / \mathrm{yr}$ equivalent sea level rise over $2003-2008$ (hence $\sim 88 \%$ of the observed rate of rise). If the small thermal expansion contribution $(0.3 \mathrm{~mm} / \mathrm{yr}$ since $2003,[30])$ is taken into account, the sea level budget is again closed.

Like observed sea level trends, thermal expansion trends are not spatially uniform (e.g., [23]). Comparing spatial trend patterns of thermal expansion and of observed sea level over 1993-2003 show striking agreement, indicating that non uniform thermal expansion (i.e., non uniform ocean heat content change) is the main cause of observed regional variability in sea level trends. However, comparing thermal expansion trend patterns for 1993-2003 with those computed over a longer period (1955-2003) shows very different geographical patterns. Investigation by Lombard et al. [23] showed that thermal expansion spatial patterns are subject to strong decadal variability related to ENSO or NAO (North Atlantic Oscillation) phenomena (i.e., the large-scale perturbations of the coupled atmosphere-ocean system). Thus sea level trend patterns observed by satellite altimetry over the last 15 years (see Fig. 5) may not be permanent features and may eventually evolve in the future towards different geographical distribution in response to decadal climate variability.

\section{Mass balance of the ice sheets}

Since the early 1990s, remote sensing observations based on airborne laser and satellite radar altimetry, INSAR and space gravimetry have provided observations of the mass balance of the ice sheets (e.g., [31-34]; see also [35] in this volume). These observations indicate accelerated ice mass loss in the recent years in coastal regions of southern Greenland, half by surface melting and runoff into the sea, and half by outlet glaciers motion draining ice from the interior. In contrast, slight mass gain is reported in central high-elevation regions [32]. Over Antarctica, remote sensing techniques report accelerated ice mass loss in the western part of the continent while the eastern region is slightly gaining mass as a result of increased precipitation. Because of these contrasting behaviours (mass loss in coastal regions and mass gain in elevated central regions), the ice sheets are not far from balance-mass loss slightly dominating mass gain-, thus have so far only modestly contributed to sea level change, in the range $0-0.5 \mathrm{~mm} /$ year only [34].

Since 2002, the GRACE mission provides a new tool for precisely measuring the mass balance of the ice sheets, with nearly complete coverage of high-latitude regions. Several recent studies have reported estimates of Greenland and Antarctica ice mass change from GRACE (see [36] for a synthesis and references herein). The GRACE results are summarized in Fig. 6 (updated from [36]), together with other estimates from laser and radar altimetry, and INSAR. For the recent years, GRACE results confirm those from other remote sensing techniques, i.e., net ice mass loss from Greenland and West Antarctica, and slight ice mass gain over East Antarctica. Besides GRACE results suggest accelerated ice mass loss since 2002, in agreement with INSAR results. However the GRACE results are still uncertain because of unrelated gravity signals from 

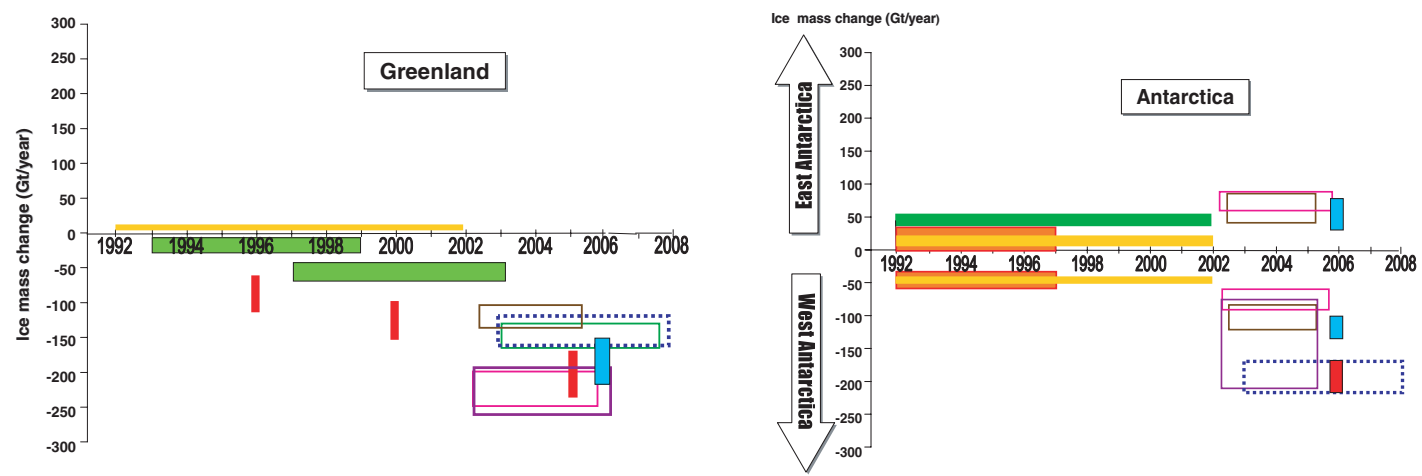

Fig. 6. Ice mass change (in Gt/year) of Greenland (left) and Antarctica (right) ice sheets based on remote sensing observations (updated from [36]).

surrounding regions and GIA contamination. Over the ice sheets, in particular Antarctica, the GIA signal may be as large as the ice mass signal itself [30].

Further research is clearly needed to improve estimates of Greenland and Antarctica mass balance and their contribution to sea level. Besides extending the time series of observations and reducing internal errors, reconciling estimates based on different techniques and eventually using them in synergy is a topic of major importance. In effect the greatest uncertainty of sea level projections from climate models is the future behaviour of the ice sheets. An important discovery of the recent years is accelerated velocities of outlets glaciers in coastal regions of the two ice sheets, a large fraction of ice mass loss occurring through dynamical processes rather than surface melting [34]. These observations suggest that the dynamical response of the ice sheets to present-day climate forcing - through acceleration of coastal glaciers associated with ice shelves reduction and break-up- plays a much larger role than previously assumed. Future dynamical instabilities of the ice sheets is a topic of major concern, given their potential impact on sea level. But comprehensive modelling of such dynamical effects is still in its infancy. Improved mass balance estimates from space observations not only will inform on the ongoing behaviour of the ice sheets but will help validating the models developed to predict future sea level change. This requires long time series of satellite observations, hence continuity of space missions.

\section{Land hydrology from space}

In the recent years, remote sensing techniques have clearly demonstrated their capability to some monitor components of the water balance in large river basins, on time scales ranging from months to decades. For example, satellite altimetry has been used for systematic monitoring of water levels of large rivers, lakes and floodplains. INSAR and passive and active microwave techniques also offer important information on land surface waters, such as changing areal extent of large wetlands, as well as depth and extent of the snow pack in boreal regions. In addition, the GRACE space gravity mission offers for the first time the possibility of directly measuring the spatio-temporal variations of the total terrestrial water storage (e.g., $[2,37,38])$. These new observations are now recognized as increasingly important to study the global water cycle whose continental branch remains very poorly known.

Terrestrial waters represent less than $1 \%$ of the total amount of water on Earth. However, they have crucial impact on terrestrial life and human needs, and play a major role in climate variability. Excluding the ice caps, fresh water on land is stored in various reservoirs: snow pack, glaciers, aquifers and other geological formations, root zone (upper few meters of the soil), and surface waters (rivers, lakes, man-made reservoirs, wetlands and inundated areas). Land waters are continuously exchanged with atmosphere and oceans through vertical and horizontal mass fluxes (evaporation, transpiration of the vegetation, surface and underground runoff). Terrestrial waters are an integral part of the global climate system with important links and feedbacks 
generated through its influence on surface energy and moisture fluxes between continental water, atmosphere and oceans. Analysis of the flow and storage of water in the global water balance is thus a key issue for the understanding of the hydrological cycle. Although improved description of the terrestrial branch of the global water cycle is now recognized as being of major importance for climate research as well as for inventory and management of water resources, the global distribution and spatio-temporal variations of continental waters are still poorly known because routine in situ observations are not available globally. In situ gauging networks have been installed for several decades in many river and lakes basins, distributed non-uniformly throughout the world. These in situ measurements provide time series of water levels and discharge rates, which are used for studies of regional climate variability as well as for socio-economic applications (e.g., water resources allocation, navigation, land use, infrastructures, hydroelectric energy, flood hazards) and environmental studies (rivers, lakes, wetlands and floodplains hydroecology). Indeed the systematic and global monitoring of these water bodies is becoming a fundamental objective of the international community, but the decline in ground-based gauge networks has dramatically increased during the last decades [39]. In many regions, data collection is restricted due to economic reasons, or the diffusion of collected data is restricted, being considered as sensitive national information. For example, more than $20 \%$ of the freshwater discharge into the Arctic Ocean is ungauged and surface water across much of Africa and portions of the Arctic is either not measured or has experienced the loss of over two thirds of the gauges [40]. Therefore, our ability to measure, monitor, and forecast global supplies of fresh water using in situ measurements is almost impossible because of the decline in the numbers of gauges worldwide and the complexity of the physics of water flow across vast lowlands. So far, global estimates of spatio-temporal change of land water storage (soil and underground waters, and snow packs) essentially rely on hydrological models, either coupled with atmosphere/ocean global circulation models and/or forced by observations. However hydrologic phenomena are so complex that it is very difficult to model the hydrological system in a simple way.

For all these reasons, space observations have the potential to improve significantly our understanding of hydrological processes at work in large river basins and their influence on climate variability and socio-economic life. Unprecedented information can be expected by combining models and surface observations with observations from space, the latter offering global geographical coverage, good spatio-temporal sampling, continuous monitoring with time, and capability of measuring water mass change occurring at or below the surface as illustrated below.

\subsection{Monitoring of surface water levels by satellite altimetry (lakes, rivers and flood plains)}

While satellite altimetry has been developed and optimized for open oceans, numerous studies used this techniques to monitor lake and river water levels (see $[41,42]$ for reviews). Water level time series for $>15$ years based on Topex/Poseidon and Jason-1 altimetry missions are now available for several hundreds continental lakes and 'virtual stations' on rivers (intersection of the satellite ground track with the river), with typical height precision of $20 \mathrm{~cm}$ and a temporal resolution of 10 days. With the denser groundtrack coverage of the ERS-2 and Envisat altimetry missions, it is several thousands of surface water bodies that can be continuously monitored. But in the latter case, the revisit time is longer (35 days). Several data bases have been developed recently, providing direct access through the internet to altimetry-derived surface water level time series (http://www.pecad.fas.usda.gov/cropexplorer/global_reservoir for lakes, the Hydroweb data base http://www.legos.obs-mip.fr/soa/hydrologie/hydroweb or lakes, rivers, floodplains and man-made reservoirs, and the 'River and Lakes' data base http://earth.esa.int/riverandlake). Fig. 7 shows an exemple of altimetry-based water level time series over lake Victoria (East Africa). For floodplains, the combination of altimetrybased water levels with radar or visible satellite imagery allows monitoring surface water volume change, in particular during flooding periods. In some cases, it is possible to estimate river discharge time series from altimetry-derived water levels. 

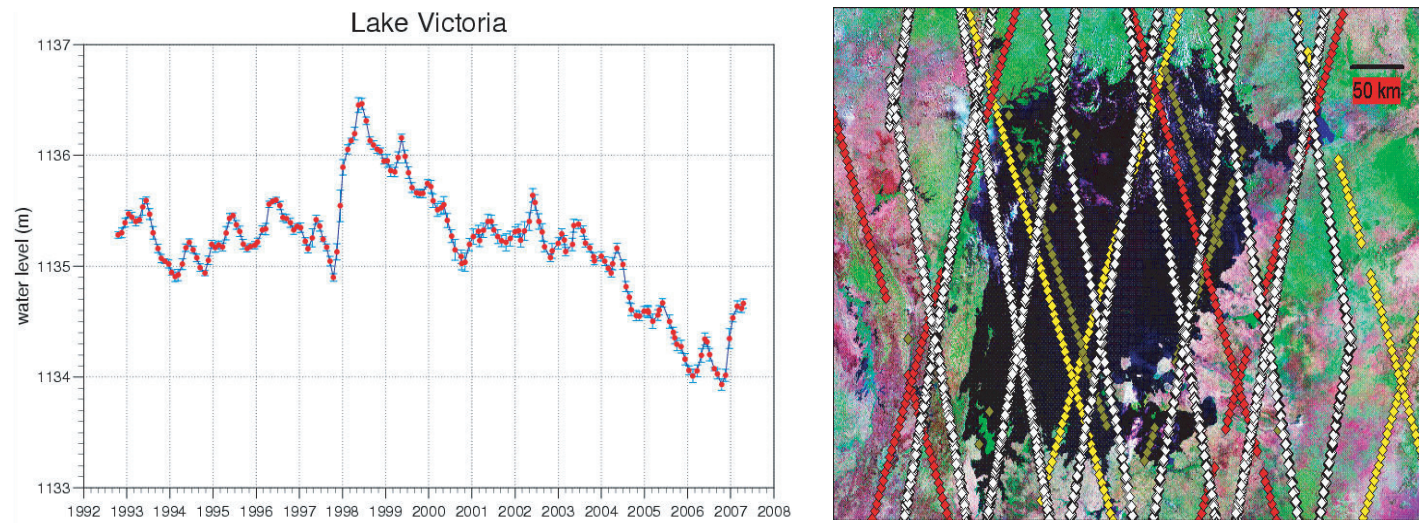

Fig. 7. Left: Lake Victoria water level time series since 1993 based on multi-satellites altimetry. Right: Satellite image of Lake Victoria on which are superimposed altimeter satellite tracks.
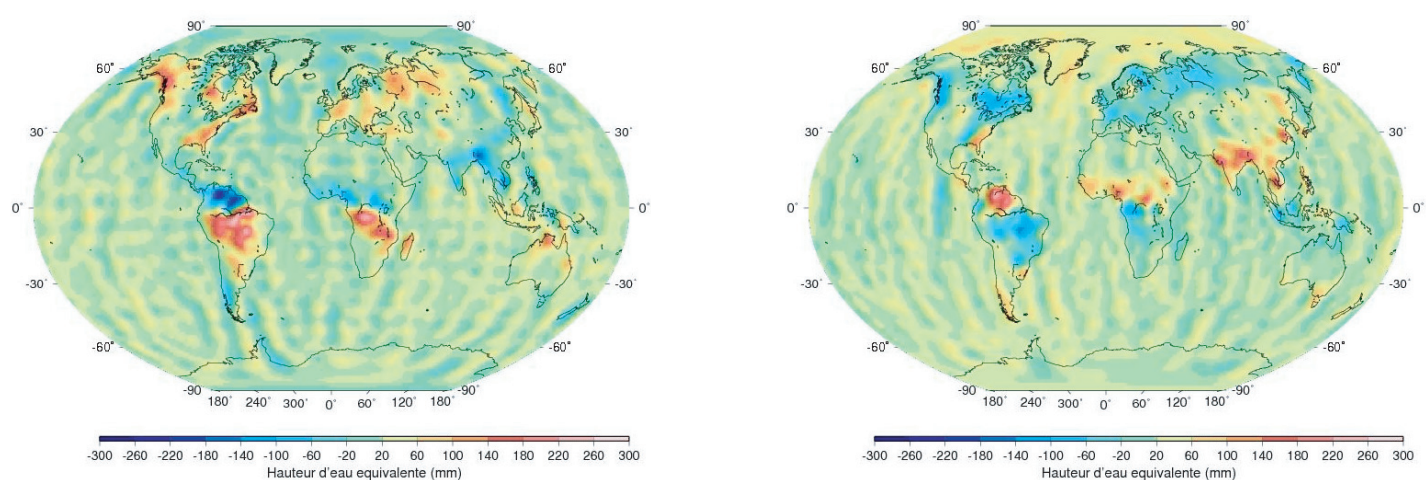

Fig. 8. Total land water storage from GRACE in mm of equivalent water height. Mars 2003 (left); August 2003 (right).

These studies show that radar altimetry is currently an essential technique for different applications: assessment of hydrological water balance, study of lake level variations, study of anthropogenic impact on lakes water storage and river flow, interaction between interannual fluctuations of lake levels and ocean-atmosphere forcing at regional scale, study of the impact of climate variability on river basin hydrology, or analysis of floodplain water storage.

\subsection{Quantifying the total land water storage using GRACE}

Since March 2002, the GRACE space mission provides an invaluable set of new observations allowing us to quantify the spatio-temporal change of the total terrestrial water storage (underground and surface waters, snow and ice mass changes). Moreover, GRACE has the capability to measure the combined effects of climatic plus anthropogenic change in terrestrial water storage.

GRACE quantifies vertically-integrated water mass changes with a precision of a few $\mathrm{cm}$ in terms of water height and a spatial resolution of $\sim 300-400 \mathrm{~km}$ (e.g., $[37,38])$. Several studies have estimated the seasonal and interannual change of total land water storage in large river basins. Because of the short GRACE data set, most studies have focussed on the seasonal hydrological cycle and showed a very good consistency with results based on global land surface models. For example, Fig. 8a,b illustrates the seasonal change of total land water storage (expressed in equivalent water height) in world river basins.

Ramillien et al. [29] estimated the water volume trend in the 27 largest river basins worldwide using GRACE data over 2003-2006 and found either positive or negative water volume change 
over that period depending on the location of the river basins. The net water volume change was slightly negative (i.e., water loss) corresponding to $-60+/-30 \mathrm{~km}^{3} / \mathrm{yr}$ over that period.

From these quantities and other measurements, it is also possible to estimate temporal variations of other hydrological variables, such as precipitation minus evapotranspiration, evapotranspitation, and total basin discharge (e.g., [43]). Most recently, GRACE-based land water storage has been used to improve global land surface models (e.g., [44-46]).

\section{Conclusions and perspectives}

Over the past decades, space observations have totally revolutionized the study of the solid Earth and its fluid envelopes. Major contributions have been obtained on Earth gravity and related Earth's internal structure, lithospheric plates, tectonic active areas, ocean dynamics, mass balance of the ice sheets, sea level rise and more recently on land hydrology. New space missions are planned in the near future, for exemple the GOCE mission to be launched soon to map the gravity field with unprecedented precision and resolution, offering important new applications in continental tectonics and ocean dynamic topography. Continuity of radar altimetry missions is also insured in the near future: the Jason-2 mission (launched in June 2008) in continuation toTopex/Poseidon and Jason-1 missions, and the SARAL/Altika mission developed jointly by India and France (launch scheduled in 2010). A new concept of wide-swath radar interferometry has been recently proposed by the scientific community to monitor surface waters with unprecedented resolution $(\sim 100 \mathrm{~m} \times 100 \mathrm{~m})$ and global coverage of worldwide rivers, lakes and floodplains within a few days [47]. Such a mission, if decided and developed by space agencies, will open a new era in land hydrology, offering important new perspectives in studies of the terrestrial water cycle, flood prediction, water resources, etc. It will also allow studying the mesoscale open ocean circulation and dynamics of coastal areas.

More generally, to study the evolution of the planet, in particular aspects related to climate change, long time series of oceanic, hydrologic, atmospheric parameters are needed. For that purpose, in addition to new mission concepts as those mentioned above, follow-on missions will definitely represent an essential component of Earth sciences research.

\section{References}

1. L.L. Fu, A. Cazenave, Satellite altimetry and Earth sciences, a handbook of techniques and applications, International Geophysics Series, Vol. 69 (Academic Press, San Diego, USA, 2001), p. 463

2. B.D. Tapley, et al., Geophys. Res. Lett. 31, L09607 (2004) doi:10.1029/2004GL019920

3. N.K. Pavlis, S.A. Holmes, S.C. Kenyon, J.K. Factor, Geophysical Research Abstracts, European Geosciences Union (2008)

4. Y. Ricard, F. Chambat, C. Lithgow-Bertelloni, C.R. Geosci. 338, 992 (2006)

5. F. Hernandez, P. Schaeffer, AVISO technical report No. AVI-NT-011-5242-CLS. CLS Editor, Toulouse, France (2000)

6. A. Cazenave, J.Y. Royer, Satellite altimetry and Earth Sciences; A Handbook of Techniques and Applications, edited by L.L. Fu, A. Cazenave (Academic Press, San Diego, USA, 2001)

7. W.H.F. Smith, D.T. Sandwell, Science 277, 1956 (1997)

8. S. Calmant, M. Berge-Nguyen, A. Cazenave, Geophys. J. Int. 151, 795 (2002)

9. K. Feigl, W. Thatcher, C.R. Geosci. 338, 1012 (2006)

10. D. Massonnet, K. Feigl, Geophys. Res. Lett. 22, 2517 (1995)

11. L.L. Fu, P.Y. Le Traon, C.R. Geosci. 338, 1063 (2006)

12. J.A. Carton, B.S. Giese, S.A. Grodsky, J. Geophys. Res. 110, C09006 (2005)

13. C. Wunsch, R.M. Ponte, P. Heimbach, J. Clim. 20 (2007) doi:10.1175/2007JCLI1840.1

14. S.J. Holgate, P.L. Woodworth, Geophys. Res. Lett. 31, L07305 (2004) doi:10.1029/2004GL019626

15. J.A. Church, N.J. White, R. Coleman, K. Lambeck, J.X. Mitrovica, J. Clim. 17, 2609 (2004)

16. J.A. Church, N.J. White, Geophys. Res. Lett. 33 (2006)

17. A. Cazenave, R.S. Nerem, Rev. Geophys. 42 (2004), RG3001, doi:8755-1209/04/2003RG000139

18. A. Cazenave, A. Lombard, W. Llovel, C.R. Geosci. (2008) (in press) 
19. G.T. Mitchum, Marine Geodesy 23, 145 (2000)

20. W.R. Peltier, Annual Rev. Earth Planet Sci. 32, 111 (2004)

21. S. Levitus, J.I. Antonov, T.P. Boyer, Geophys. Res. Lett. 32, L02604 (2005) doi: 10.1029/2004GL021592

22. J. Antonov, S. Levitus, T.P. Boyer, Geophys. Res. Lett. 32 (2005) doi:10.1029/2005GL023112

23. A. Lombard, A. Cazenave, S. Guinehut, P.-Y. Le Traon, C. Cabanes, Ocean Dyn. 56, 445 (2006) doi:10.10007/s10236-005-0046-x

24. N.L. Bindoff, J. Willebrand, V. Artale, A. Cazenave, J. Gregory, S. Gulev, K. Hanawwa, C. Le Quéré, S. Levitus, Y. Nojiri, C.K. Shum, L. Talley, A. Unnikrishnan, In Climate change 200\%: The physical Science Basis. Contribution of Working Group I to the Fourth Assessment report of the Intergouvernmental Panel on Climate Change, edited by S. Solomon, D. Qin, M. Manning, Z. Chen, M. Marquis, K.B. Averyt, M. Tignor, H.L. Miller (Cambridge University Press, Cambridge, UK, New York, USA, 2007)

25. G. Kaser, J.G. Cogley, M.B. Dyurgerov, M.F. Meier, A. Ohmura, Geophys. Res. Lett. 33, L19501 (2006) doi:10.1029/2006GL027511

26. M.F. Meier, M.B. Dyurgerov, U.K. Rick, S. O’Neel, W.T. Pfeffer, R.S. Anderson, S.P. Anderson, A.F. Glazovsky, Science 317, 1064 (2007)

27. E. Rignot, J.L. Bamber, M.R. Van den Broecke, C. Davis, Y. Li, W.J. Van de Berg, E. Meijgaard, Nature Geoscience 1, 106 (2008) doi:10.1038/ngeo102

28. T. Ngo-Duc, K. Laval, Y. Polcher, A. Lombard, A. Cazenave, Geophys. Res. Lett. 32, L09704 (2005) doi:10.1019/2005GL022719

29. G. Ramillien, S. Bouhours, A. Lombard, A. Cazenave, F. Flechtner, R. Schmidt, Global Planet Change 60, 381 (2008)

30. A. Cazenave, S. Guinehut, G. Ramillien, W. Llovel, K. DoMinh, M. Ablain, Global Planet Change (submitted)

31. W. Krabill, E. Hanna, P. Huybrechts, W. Abdalati, J. Cappelen, B. Csatho, E. Frederick, S. Manizade, C. Martin, J. Sonntag, R. Swift, R. Thomas, J. Yungel, Geophys. Res. Lett. 31 (2004) doi:10.1029/2004GL021533

32. H.J. Zwally, M.B. Giovinetto, J. Li, H.G. Cornejo, M.A. Beckley, A.C. Brenner, J.L. Saba, D. Yi, J. Glaciology 51, 509 (2005)

33. E. Rignot, P. Kanagaratnam, Science 311, 986 (2006)

34. P. Lemke, et al., Climate change 200\%: The physical Science Basis, edited by S. Solomon, D. Qin, M. Manning, Z. Chen, M. Marquis, K.B. Averyt, M. Tignor, H.L. Miller (Cambridge University Press, Cambridge, UK, New York, USA, 2007)

35. M. Van den Broeke, Eur. Phys. J. Conf. 1, 171 (2009)

36. A. Cazenave, Science 314, 1250 (2006)

37. J. Wahr, S. Swenson, V. Zlotnicki, I. Velocogna, Geophys. Res. Lett. 31, L11501 (2004) doi: 10.1029/2004GL019779

38. G. Ramillien, F. Frappart, A. Cazenave, A. Guentner, Earth Planet. Sci. Lett. 235, 283 (2005)

39. D.E. Alsdorf, D.P. Lettenmaier, Science 301, 1492 (2003)

40. I.A. Shiklomanov, Comprehensive Assessment of the Freshwater Resources of the World, World Meteorological Organization (1997)

41. J.F. Crétaux, S. Birkett, C.R. Geosci. 338, 1098 (2006)

42. S. Calmant, F. Seyler, C.R. Geosci. 338, 1113 (2006)

43. G. Ramillien, F. Frappart, A. Guntner, T. Ngo-Duc, A. Cazenave, Water Resour. Res. 42, W10403 (2006) doi:10.1029/2005WR004331

44. S.C. Swenson, P.C.D. Milly, Water Resour. Res. 42 (2006) doi:10.1029.2005WR004628

45. T. Ngo-Duc, K. Laval, J. Polcher, G. Ramillien, A. Cazenave, Water Resour. Res. 43, W04427 (2007) doi:10.1029/2006WR00494

46. A. Guentner, Survey in Geophysics, Thematic Issue on Hydrology from Space (2008) (in press)

47. D. Alsdorf, L.L. Fu, N. Mognard, A. Cazenave, E. Rodriguez, D. Chelton, D. Lettemaier, EOS, Transactions, AGU 88, 253 (2007) 